\title{
UN ROMÁNTICO COMPROMETIDO: JOSÉ MARÍA BONILLA Y DON ÁLVARO DE LUNA, CONDESTABLE DE CASTILLA (1838)
}

\author{
Leticia Placín Alonso \\ Universidad de Vigo
}

\begin{abstract}
Resumen
El presente trabajo centra su atención en el estudio de Don Álvaro de Luna, Condestable de Castilla, drama histórico en prosa y verso del escritor valenciano José María Bonilla, estrenado en Valencia en 1838. En ese momento, solo un lustro después de la muerte de Fernando vII y en plena guerra carlista, Bonilla, periodista y fundador él mismo de diversos periódicos de corriente liberal encarna los postulados de la primera generación romántica. Como dramaturgo, el drama histórico le sirve para manifestar su posicionamiento frente a los acontecimientos políticos de su época, a partir de una estética romántica cuyos principales rasgos analizo en el título que me ocupa.

Palabras Clave: José Ma Bonilla, Álvaro de Luna, Juan II, drama histórico, romanticismo.
\end{abstract}

\section{Abstract}

The present paper is centred on the study of Don Álvaro de Luna, Condestable de Castilla, historical drama both in prose and verse, by the Valencian writer José María Bonilla, which was first performed in Valencia in 1838. At that moment, just five years after the death of Fernando VII and in the middle of the Carlist War, Bonilla, journalist and founder himself of several liberal-thinking journals embodies the postulates of the first romantic generation. As a playwright, historical drama is used by him to voice his positioning regarding the political events of his time, based on romantic aesthetics whose main traits I analyse in the present title.

KeY wORDS: José M ${ }^{a}$ Bonilla, Álvaro de Luna, Juan II, historical drama, romanticism.

En el siglo XIX el auge de la prensa posibilita la incorporación de un gran número de escritores al mundo cultural y literario. Muchos nombres de autores de la época, hoy poco conocidos y estudiados, participan de este florecer de las letras, no solo a través de las publicaciones periódicas, sino también con sus textos de creación, como es el caso de José María Bonilla. Valenciano, liberal de la primera generación romántica Recibido: 11-07-2017 / Aceptado: 03-08-2017 
y comprometido con la causa revolucionaria, aborda en sus escritos la problemática social, política y económica de su siglo, desde una perspectiva tanto periodística como literaria. Tanto es así que su primer drama histórico, Don Álvaro de Luna, Condestable de Castilla (1838), escrito en pleno auge del teatro romántico, recoge entre sus versos auténticos alegatos liberales en contra del absolutismo.

La obra se representó en el Teatro Principal de Valencia en 1838 y, posteriormente, en el Teatro de la Cruz de Madrid ${ }^{1}$. Años más tarde, en octubre de 1845, se reestrena en Zaragoza, suscitando juicios críticos poco favorables ${ }^{2}$. El texto fue publicado en el volumen Poesías, en 1840, misceláneo, junto con las poesías del autor y un prólogo muy elogioso de Vicente Boix. Se conserva otra edición de 1856, publicada en Madrid. El argumento central del drama gira en torno a la figura de don Álvaro de Luna y las luchas por el poder en Castilla durante el siglo $\mathrm{xv}$, revueltas evocadas por el romanticismo como metáforas de su propio tiempo, ya que los dramaturgos decimonónicos observaban en los personajes de la corte de Juan II, de quien Luna es condestable, figuras y situaciones paralelas a sus propias contiendas políticas y sociales, como tendré ocasión de argumentar en este trabajo.

José María Bonilla nace en Valencia en los primeros tiempos de la Guerra de la Independencia española, en agosto de 1808. Su vida estará marcada por la revolución burguesa y su devenir por la política, el periodismo, la abogacía y la literatura, disciplina esta a la que - como a la música, la arquitectura y la pintura - se siente

\footnotetext{
${ }^{1}$ D. Hidalgo, Diccionario General de la Bibliografía Española, Madrid, Julián Pena, 1867, vol. II, p. 335. En el servidor Parnaseo de la Universidad de Valencia se pueden consultar los carteles de las reposiciones valencianas de 1840, 1841, 1844 y 1856. En el de 1840 (16 de noviembre) leemos: «Su hermosa y rápida versificación, sus brillantes escenas y las delicadas correcciones que el autor ha creído hacer después de su primera representación, merecerán tal vez un éxito distinguido. [...] El autor, después que ha embellecido su creación, ha colocado al noble condestable en la posición sublime que sus altos hechos le concedieron entre los nombres más célebres de nuestra abundante historia. El último acto, sobre todo, es una bella inspiración y el público, apreciador del genio y de la aplicación, sabrá formar el debido concepto de su joven autor, cuyo nombre es bien conocido de sus paisanos» (Parnaseo, http:/ / parnaseo. uv.es/carteles/cartel_T_id.asp?id=Funci\%F3n \%20extraordinaria \%20para \%20el\%20lunes\%2016\%20 de\%20noviembre\%20de\%201840 [consulta: mayo 2017]).

${ }^{2}$ El corresponsal en Zaragoza de El Clamor Público remite el 25 de octubre la siguiente reseña: «Anoche se puso en escena una composición nueva en este teatro, debida a la pluma del señor Bonilla, en cinco actos, titulada Don Álvaro de Luna. Todo su argumento consiste en que el señor rey don Juan II sueña unos jeroglíficos de hacha, verdugo, sombras y fantasmas; y los traduce, a lo rey, en que ha de morir su favorito el de Luna, porque corteja a la reina. Luego sale un obispillo (esta es palabra del autor) y dice que le han dicho que don Álvaro y la reina hacen picardigüelas; los grandes, la reina y todo el mundo acusan a don Álvaro, y hasta el tribunal, compuesto de doce jueces condena al ministro por once votos sin oírle siquiera: en fin, el poeta valenciano, por hacerle algún favor, ni aún lo pone en capilla para matarle, y desde la cárcel, donde estaba don Álvaro bien ajeno de morir, se le llevan unos cuantos hombres con hachas encendidas al patíbulo. Después viene la grandeza y la reina y el rey y todos a la cárcel para ver el espectáculo unos, la reina para pedir por el valido desvalido, y el juez, que no quiso firmar la sentencia, también le tira al rey en sus hocicos la toga porque no quiere ya ser juez [...]». (Anónimo, «Crónica de teatros», El Clamor Público, 30 octubre [1845], p. 4.).
} 
inclinado desde la niñez.

Son escasos los trabajos sobre este autor y su obra. Sus biógrafos (Laullé en el siglo XIX y, más recientemente, Laguna y Ortega ${ }^{3}$ ) coinciden en destacar su compromiso público. Tras sus estudios de Derecho y su título de Individuo Honorario en la Academia de Práctica Forense su militancia liberal le ocasionará diversos conflictos. Es acusado de participar en tramas conspiratorias contra Fernando VII, motivo por el cual ingresa en la cárcel unos meses. Se le desautoriza aludiendo a su condición de «hijo de negro», término con el que los realistas se referían despectivamente a los liberales de segunda generación que, como sus padres, sufren represalias por su oposición al rey. Por todo ello se le destierra a Almonacid, donde permanece con su familia hasta 1830, en medio de una ruinosa situación económica derivada de las multas que le son impuestas, tanto al padre como al hijo ${ }^{4}$.

Su faceta literaria comienza a manifestarse hacia el año 1829, en que publica sus primeras poesías. Estas composiciones fueron muy bien recibidas por el público, hecho que le incita a continuar con sus colaboraciones en el Diario de Valencia. Al año siguiente se anima con el teatro y publica las tragedias Dion triunfante en Siracusa y Los reyes de Esparta. La primera se estrena en Valencia en 1833 y, al igual que sus poesías, es acogida favorablemente, de modo que es publicada en folletines en El Catalán. Dejando a un lado los textos estrictamente literarios, Bonilla escribe no solo reseñas de teatro o de poesía, sino también artículos de diversa temática en el Diario Mercantil, del que es redactor y fundador, además de dedicarse a la pintura de retratos y caricaturas que se difunden en prensa 5 .

Durante la primera Guerra Carlista (1833-1840) Bonilla acepta diferentes puestos políticos. En 1834 es nombrado alcalde de Jérica, participa en la Milicia, organiza él mismo una sección de caballería en la que es comandante y se traslada como alcalde y juez de primera instancia a Aranda, hasta que tras diversos incidentes presenta su dimisión 6 .

Regresa a Valencia centrándose plenamente en el periodismo. Continúa entonces escribiendo para el Diario Mercantil, pero tiene en mente un proyecto más ambicioso, su gran creación, uno de los pilares de la lengua y de la cultura valenciana: el 1 de febrero de 1837 publica El Mòle, periódico en valenciano de enorme éxito que

\footnotetext{
${ }^{3}$ A. Laguna y E. Ortega, Un periodista romántico en la revolución burguesa: José María Bonilla, Valencia, Papers de Prensa, 1989. J. Laullé, Biografía en abreviatura de D. José María Bonilla, Valencia, Imprenta de José Domenech, 1871.

${ }^{4}$ J. Laullé, ob. cit., p. 5; A. Laguna y E. Ortega, ob. cit., p. 11.

${ }^{5}$ J. Laullé, ob. cit., p. 5-6.

${ }^{6}$ Ibidem, p. 7.
} 
será duramente censurado durante su existencia por su carácter crítico y satírico.

El Mòle se hacía eco, a través del costumbrismo, del momento político y social de la época. Lo más característico de esta publicación era el esquema ficcionalizado que representaba. En sus artículos un campesino opina sobre la situación sociopolítica del momento y aborda las decisiones gubernamentales y sus consecuencias. El empleo del valenciano en El Mòle lo convierte en uno de los primeros hitos del movimiento que aparecerá hacia 1874, la Reinaxença catalana:

[...] ¿Por qué opta en favor de la lengua que utilizan los campesinos y la menestralía urbana? La explicación la podemos situar en dos niveles complementarios: en primer lugar, porque Bonilla se convierte en un personaje más de su periódico; un personaje que comparte con el resto los temores, las angustias, las denuncias... y, por supuesto, la lengua. En segundo lugar, ese grupo de protagonistas de El Mòle no son una opción gratuita, son los marginados de la revolución, los amenazados por la proletarización; son una prueba del compromiso de Bonilla. En consecuencia, la explicación se localiza en los efectos que la transformación burguesa estaba provocando: artesanos arruinados, campesinos expulsados de la tierra. Por tanto, optar por la lengua de estas capas sociales significa, en alguna medida, optar por su defensa ${ }^{7}$.

En el contexto de la primera guerra carlista, con la desamortización en marcha y el fin del antiguo régimen, Bonilla se inclina por la defensa del pueblo desde una perspectiva liberal. Sin embargo, la postura de El Mòle fue muy crítica tanto con los liberales moderados como con los carlistas, representantes del absolutismo contra el que Bonilla luchará toda su vida y al que ridiculizará constantemente en todas sus publicaciones. También somete a examen a los republicanos, aunque en menor medida, e incluso a los progresistas, representados por Mendizábal, de cuyo gobierno denuncia las verdaderas hambrunas que había provocado entre el campesinado. El Mòle suspende su publicación tan solo un año después de su primer número ${ }^{8}$.

Bonilla funda un nuevo periódico en 1838, El Desengaño, al tiempo que escribe su drama Don Álvaro de Luna, Condestable de Castilla. En 1839 sale a la luz El Cisne, periódico ilustrado de carácter científico, artístico y literario en el cual difunde sus comedias Casilda, Una mujer como muchas, la biografía de Lord Byron y artículos de diversa temática. Como pintor publica algunos retratos de escritores y artistas célebres, también dibuja en piedras litográficas y graba en madera para la ilustración literaria y en prensa9.

A finales del año 1840 reaparece El Mòle, contando esta vez con un gran número

\footnotetext{
${ }^{7}$ A. Laguna y E. Ortega, ob. cit., p 18.

8 Ibidem, pp. 21-24.

${ }^{9}$ J. Laullé, ob. cit., p. 8. 
de suscriptores. En su nueva etapa el periódico vuelve a ser perseguido, esta vez especialmente por la iglesia ${ }^{10}$. Después, Bonilla se traslada a Barcelona, lugar en el que pasa dos años dedicándose a la abogacía y escribiendo como redactor único en los periódicos de La Ley y El Popular. En este último se publica un manifiesto de la ideología liberal que sirve como presentación del escritor ante los lectores del periódico. Sirva su interés para excusar la extensión de la cita que reproduzco:

[...] firmes en nuestra opinión y en los principios de progreso constante y tolerancia absoluta que tenemos proclamados y que adoptamos como letra o símbolo de nuestra fe política al dar al Popular la extensión que hoy guarda, y convencidos íntimamente de nuestra posición actual y de la suerte que amaga a nuestro país, seguiremos escribiendo bajo la única bandera de salvación que debemos tremolar, y en torno de ella llamaremos constantemente a los nombres de la libertad, a los españoles puros y honrados que no hayan negado sus sacrificios de buena fe a la existencia y al honor de su país. Desnudos de toda pasión degradante que pueda despertar en nosotros un sentimiento de encono por cualquiera disidencia en el modo de ver la marcha de las cosas y de los acontecimientos, todo propondremos a la unión que debe constituir la fuerza invencible en la defensa de nuestra libertad, de nuestra independencia nacional, de nuestro honor. Aquí todos somos y seremos españoles, porque deseamos ser libres y desarmaremos por lo mismo vuestros brazos delante del despotismo que amenaza a devorarnos; queremos las cosas claras y no nos satisfacen sus meras teorías; del gobierno exigimos buen gobierno; de los legisladores buenas leyes y de los magistrados justicia. Decimos todo esto a propósito de ingresar en nuestra redacción dos nuevos colaboradores, uno de ellos muy conocido por los triunfos literarios que ha alcanzado [...] Don José María Bonilla, joven escritor, redactor que fue del Cisne de Valencia y autor de varias obras que han merecido el más distinguido acogimiento ${ }^{11}$.

Meses más tarde, cuando cesa su actividad en este periódico, el mismo Bonilla escribe una nota de despedida responsabilizándose de las opiniones vertidas en sus artículos ${ }^{12}$.

Ya entrado el año 1843, y de vuelta Bonilla a Castellón, recibe una carta del general Prim citándole en Madrid. La estancia en la capital se alarga hasta 1848, año en el que se produce la revolución, que coincide con la muerte de su padre. Durante este tiempo fue invitado por Ayguals de Izco a participar en $L a$ Risa, en la que publicó algunos artículos y composiciones artísticas ${ }^{13}$. Destaca su obra Cuento extravagantemente inaudito. En el año 1844 publica en La Cotorra, El Tabalet y poco después en El Espectador. Se dedica a hacer copias de pintores ilustres, como Murillo, Rafael, Tiziano, Bosch o

\footnotetext{
${ }^{10}$ Lo que va a ocasionarle problemas a El Mòle esta vez es la publicación de la historia de los papas, lo que deriva en que la curia eclesiástica forme una causa de fe al propio Bonilla (J. Laullé, ob. cit., p. 9).

${ }^{11}$ Anónimo, «A nuestros lectores», El Popular. Diario de los Intereses de Cataluña, (30 septiembre 1841), s. p.

${ }^{12} \mathrm{~J}$. M. Bonilla, «A nuestros suscritores», El Popular. Diario de los Intereses de Cataluña, (8 diciembre 1841), s. p.

${ }^{13}$ A. Laguna y E. Ortega, ob. cit., pp. 89-91.
} 
Velázquez, entre otros, que vendía a numerosas personalidades de la época ${ }^{14}$.

A su regreso a Valencia, en el año 1851, publica el periódico satírico La Cantárida y durante este tiempo se aleja de la política y de la milicia. En 1855 es elegido por tercera vez capitán de cazadores, poco después comandante del batallón de artillería y también síndico del ayuntamiento, puesto que no acepta. En este momento, Bonilla se estaba centrando en la publicación de la tercera entrega de El Mòle, que fue recibido, una vez más, con éxito.

Otro de sus desengaños políticos fue el desarme de la milicia en Valencia y el triunfo de $\mathrm{O}^{\prime}$ Donell $^{15}$. Tras estos hechos regresa a Castellón, abre un despacho de abogados y decide apartarse del mundo periodístico y literario, aunque en ocasiones sigue publicando algún artículo o poesías en la prensa local. Años después retoma la cuarta entrega del Mòle, pero esta vez intenta que no haya en él contenidos subversivos. Solo un año más tarde lo convierte en un periódico plenamente político como suplemento a Los dos reinos. Desengañado y cansado de la política, publica un folleto titulado España y los dos partidos en 1869, en el cual expone qué ha de ser la revolución, a su juicio. En 1870 ve la luz la última temporada de El Mòle, en la que critica duramente «cómo los partidos liberales entienden en España la libertad y la república» ${ }^{16}$. Muere en el año 1880, siendo plenamente consciente del olvido en el que ha caído tanto su vida como su obra ${ }^{17}$.

Bonilla fue un intelectual interesado en la cultura y en su difusión, en la denuncia y en la crítica, esperanzado en el triunfo de una revolución verdaderamente liberal, pero desengañado ante las constantes decepciones políticas y la persecución a la que fue sometido El Mòle. Aboga por la educación para todos como principio revolucionario y crítico, de ahí su afán por convertir su periódico en un instrumento que sirviese de aprendizaje y de vehículo de opinión para el campesinado. Su labor como miliciano, político, abogado, pero sobre todo como periodista y escritor fue incansable. Buen ejemplo del intelectual políticamente comprometido, «lleno de melancolía y resignado al desengaño» ${ }^{18}$, obtuvo uno de sus momentos de gloria literaria con el estreno de sus obras teatrales durante el Trienio Moderado.

\footnotetext{
${ }^{14} \mathrm{~J}$. Laullé, ob. cit., pp. 11-12.

${ }^{15}$ Este triunfo se produce tras el golpe de estado perpetuado por el propio O' Donell en contra del Gobierno de Espartero, poniendo fin así al Bienio Progresista (1854-1856). Bonilla se encontraba de nuevo en Madrid en el momento del golpe - julio de 1856 - por cuestiones periodísticas; en Valencia, mientras, sucede la colisión entre la milicia y el ejército (J. Laullé, ob. cit., p. 14).

${ }^{16}$ Ibidem, p. 15.

${ }^{17}$ A. Laguna y E. Ortega, ob. cit., p. 182.

${ }^{18}$ E. A. Peers, Historia del movimiento romántico español, Madrid, Gredos, 1973, vol. I, p. 260.
} 
El drama Don Álvaro de Luna, Condestable de Castilla se anuncia en varios periódicos de la época como «drama en prosa y verso, en lenguaje del siglo xvI, representado por primera vez en el teatro de Valencia en 1838». Posteriormente, el mismo periódico corrige el error y sitúa el argumento en el siglo $\mathrm{xv}^{19}$.

El siglo XIX es un periodo políticamente convulso que invita a Bonilla a volver sus ojos al no menos complejo tiempo de don Álvaro de Luna, condestable de Juan II de Castilla, cuyo reinado fue contemplado por los intelectuales del XIX, como antes he comentado, en paralelo con sus propias contiendas políticas. Don Álvaro se convierte en un personaje que despierta fascinación entre los escritores románticos. Simultáneamente al estreno del drama de José María Bonilla, se lleva a escena en Valladolid Los cortesanos de don Juan II, de Jerónimo Morán $(1838)^{20}$ y poco después, en Madrid, la pieza de Antonio Gil y Zárate Don Álvaro de Luna (1840)21. Como estos títulos, el de Bonilla gira en torno al poder casi absoluto del maestre de Santiago, cuyos privilegios temen los demás nobles castellanos y el alto clero, personajes que se conjuran contra él hasta provocar su fin. A esta trama de conspiraciones cortesanas hay que sumar los conflictos políticos que se mencionan a lo largo del drama: los navarros invaden el norte y los musulmanes amenazan desde el sur. Todo ello se relaciona, a su vez, con un argumento original de la obra: don Álvaro está enamorado de la reina doña Isabel, circunstancia esta que contribuirá también a su definitiva caída en desgracia.

A juicio de Laguna y Ortega ${ }^{22}$ la figura de don Álvaro puede tener cierto paralelismo histórico con Mendizábal. Al igual que el protagonista del drama, Mendizábal representaba el más absoluto poder y manejaba la escena pública desde la presidencia del gobierno a partir de septiembre de 1835. Este político había promovido ciertos decretos desamortizadores que le habían granjeado el descontento de parte del clero y de la nobleza, lo que contribuyó a su alejamiento de la política en varias ocasiones, en 1836 y 1837, como el propio don Álvaro. Además, Mendizábal había tenido responsabilidades de guerra en el conflicto carlista, en cuyo frente norte (País Vasco y Navarra) tienen lugar en esos años importantes batallas ${ }^{23}$, paralelismos estos que evocan los versos del drama donde se alude a la problemática situación del siglo

\footnotetext{
${ }^{19}$ Anónimo, «Gacetín urbano», El Constitucional, 14 de mayo (1840) p. 4; Anónimo, «Producciones literarias de don José María Bonilla», El Constitucional, 30 de agosto (1841) p. 4.

${ }^{20}$ M. Ribao Pereira, «Una relectura romántica de la corte: Los cortesanos de don Juan II, de J. Morán» en J. M. González Herrán et al. (eds.), La historia en la literatura del siglo XIX. Barcelona, Universitat de Barcelona, 2017, pp. 651-660.

${ }^{21}$ M. Ribao Pereira, « ¿Y si el corazón miente? Los (falsos) poetas cortesanos de Juan II vistos por los dramaturgos románticos», en A. Cancellier (ed.), El corazón es centro, Padua, Universidad de Padua, 2017 (en prensa).

${ }^{22}$ A. Laguna y E. Ortega, ob. cit., p. 37.

${ }^{23}$ I. Burdiel, Isabel II: una biografía (1830-1904), Madrid, Taurus, 2010.
} 
$\mathrm{XV}$, como veremos más adelante.

El complejo entramado político y social de los años treinta del siglo xIX evidencia un escenario de lucha con los carlistas y de continuos enfrentamientos entre liberales moderados y liberales progresistas. Estos conflictos son reescritos por los literatos decimonónicos en paralelo a los de los ricoshombres de Castilla, nobles que aborrecen al condestable por su infinito poder y que traman venganza para reducir su dominio económico y social y para menguar su influencia sobre el monarca. Además de todo ello, hay un motivo de igual importancia en el desarrollo dramático que provoca la desconfianza del rey: el amor que doña Isabel y don Álvaro se profesan, una pasión prohibida y afrentosa para Juan II, una traición que hace que se posicione, definitivamente, en contra del condestable.

En el drama de Bonilla confluyen, pues, dos tramas. Por un lado, se presentan las conspiraciones políticas basadas en hechos históricos a los que los románticos acceden a partir de crónicas medievales, reeditadas pocos años antes, como la Crónica del condestable don Álvaro de Luna, y de ensayos de amplia difusión como el de Quintana ${ }^{24}$. Los hechos históricos que se presentan en el drama se ajustan al relato de estas fuentes y sus personajes principales responden a figuras bien conocidas: don Álvaro de Luna, el rey don Juan II, la reina doña Isabel, el contador del reino don Alonso de Vivero, los nobles - conde de Haro, conde de Plasencia, marqués de Santillana - , el obispo don Alonso, y don Juan, probablemente Juan de Velázquez, uno de los jueces de Castilla que condena a Luna, quien al final del drama de Bonilla renuncia a su cargo ante la evidencia de la injusticia que acaba de cometerse ${ }^{25}$. También están presentes otras figuras históricas, como la condesa de Ribadeo, e incluso el criado de don Álvaro, Diego Gotor. Hay menciones a otros nombres reales, como la esposa de don Álvaro, doña Juana Pimentel, el arzobispo de Toledo o el duque de Alba.

La otra línea, la amorosa, es creación del escritor y supone el punto de inflexión que determina el destino del condestable, trasciende lo personal y se transforma en una excusa de los nobles para eliminar a don Álvaro del panorama político y social de la corte. Será durante el primer acto cuando se caracterice a todos los personajes y se destaquen los protagonistas del drama: don Álvaro de Luna, el rey don Juan y la

\footnotetext{
${ }^{24}$ La Crónica de don Álvaro de Luna es editada por don Josef Miguel de Flores en 1784 (Madrid, Sancha). Manuel José Quintana sintetiza en su Vida de españoles célebres. Don Álvaro de Luna (Madrid, Imprenta de Burgos, 1833) los juicios históricos sobre el condestable desde el siglo XVI.

${ }^{25}$ Juan de Velázquez es el protagonista del romance El castigo de un mal juez, de Adolfo de Castro y Rossi, publicado en 1859, que narra los terribles remordimientos de este juez, que enloquece y muere perseguido por el fantasma de don Álvaro de Luna. F. Codeseda Troncoso, «Un romance decimonónico desconocido: El castigo de un mal juez, de Adolfo de Castro y Rossi», en R. Hernández Arias, G. Rivera Rodríguez, S. Cuba López y D. Pérez Álvarez (eds.), Nuevas perspectivas literarias y culturales, Vigo, MACC-ELICIN, 2016, pp. 97-104.
} 
reina doña Isabel, actores del triángulo amoroso. Y ya en la primera escena del drama se acercan al público los datos históricos, pues don Álvaro y su amigo don Alonso de Vivero mantienen una conversación en donde analizan las posibles revueltas políticas que se avecinan. En definitiva, las dos líneas argumentales, que en un principio podrían parecer separadas, confluirán íntimamente quedando totalmente integradas, conformando de este modo un drama románticamente verosímil a ojos del espectador o del lector del siglo XIX.

Bonilla presenta una serie de personajes y acciones que, definitivamente, asumen un gran paralelismo con la serie de acontecimientos que precedieron a la composición y al estreno de la pieza, como he señalado anteriormente. Para representar dichos conflictos sociales y políticos, el dramaturgo busca un tema que es análogo a ellos $\mathrm{y}$ encuentra en los enfrentamientos cortesanos del siglo $\mathrm{xV}$ una excusa para hacer referencia a su tiempo, a través de acciones y personajes históricos que examinaré a continuación.

Don Álvaro es la figura central sobre la que se construye el drama. Al comienzo de la obra el condestable se presenta a sí mismo como un hombre poderoso, como el verdadero monarca castellano, haciendo gala de una prepotencia que será visible casi hasta el final. Luna reivindica su libertad personal, la superioridad de su yo cada vez que se proclama rey de Castilla. Es consciente de que los nobles de la corte se agrupan para hacerle frente ${ }^{26}$ y de que sus enemigos se servirán de las habladurías para provocar su caída.

En el personaje de don Álvaro hay cierta reivindicación romántica del hombre hecho a sí mismo, valioso por sus obras, no por su linaje ${ }^{27}$, de ahí su oposición a los miembros de la aristocracia y de la iglesia. Bien es cierto que traiciona a don Juan II al amar a doña Isabel y autoproclamarse rey de Castilla, pero también lo es que no vulnera nunca los intereses políticos del monarca, por el que ha luchado y al que profesa cariño. Ha velado en todo momento por los beneficios de la corona castellana, como así reconoce incluso la propia reina (I, 5, p. 21). Luna es, en definitiva, paradigma del héroe romántico de los años 30 , que se cree

superior a la condición general y cuyas ambiciones son combatidas por fuerzas antagónicas evidentemente malas. La reacción será una tristeza (llamada melancolía, esplín, tedio, hastío o fastidio universal) que el héroe proyecta sobre el

\footnotetext{
${ }^{26}$ En adelante cito por la edición de 1856. Anoto acto en romanos y cuadro (si lo hay) y escena en arábigos. «Álvaro: [...] Muchos años ha que pretenden elevarse sobre mi ruina. Bien sé que los linajes de los Zúñigas, de los Haros y Santillanas hacen liga contra mí». (I, 1, p. 6).

${ }^{27}$ J. Escobar, «Romanticismo y revolución», en D. T. Gies (ed.), El Romanticismo, el escritor y la crítica, Madrid, Taurus, 1989, pp. 320-335.
} 
mundo que le rodea ${ }^{28}$.

A pesar de su prepotencia y altanería, los espectadores o los lectores no le juzgarán negativamente porque sus enemigos son mucho más infames que él. Solo será una víctima cuando finalmente sea condenado a muerte por el consejo de jueces; mostrará entonces su faceta de héroe resignado, que mantiene su grandeza y honor en la adversidad.

Otro vértice del conflicto dramático es el rey don Juan II. En la Crónica de don Álvaro de Luna, editada por Flores en 1784, se señala su incapacidad para gobernar y sus inexistentes dotes para dominar la corona y la corte, por lo que es frecuente su caracterización literaria como un personaje a la sombra de don Álvaro, como en este drama. En él la desconfianza del monarca hacia el condestable se manifiesta desde su primera aparición y el mismo don Álvaro es consciente de ello. Desde las escenas iniciales destaca la tristeza de su ánimo, sentimiento motivado por el sueño que dice haber tenido. Recita entonces unas «trovas» que no son otra cosa que la declaración de la desgracia que está por venir, anticipo premonitorio de su propia deshonra.

Su desconfianza hacia don Álvaro se transforma en odio, tras la conversación con el obispo don Alonso en el acto I, y en miedo: «don Álvaro me hace ofensa y tiemblo de castigarle» (I, 4, p. 16). Recobra parcialmente su autoridad tras escuchar oculto a Luna y a doña Isabel en la capilla, jura venganza y promete ante los nobles alejar al condestable de la Corte (II, 6, p. 33). Incluso llega a mostrarse compasivo y envía algunos avisos al maestre para que huya. Hacia el final (IV-1, 4, pp. 65-66), le muestra su afecto e incluso podría parecer que quiere salvarle. Acatar la sentencia de muerte de Luna le devuelve, definitivamente, a su posición de debilidad y sometimiento a la voluntad interesada de los nobles que intrigan en la corte.

El tercer eje del drama es la reina doña Isabel; su primera aparición en escena está motivada por la llamada del rey, que la interroga sobre don Álvaro. La impresión inicial del espectador o del lector es que doña Isabel no tiene ninguna relación con el condestable. El monarca insinúa hasta tres veces la amorosa cercanía, a lo que la dama responde ofendiéndose y pidiendo respeto desde su posición. Inmediatamente después, cuando la reina se queda sola, reconoce el amor que siente por Luna, pero también su alto sentido del honor, que antepone al sentimiento: «honor quiero más que a vos;/ y sin él, la sepultura» (I, 6, p. 22).

Los amantes mantienen una única conversación en la obra, al inicio del segundo acto. Don Álvaro amenaza a la reina («hacéis bien en darme afrenta; en arrojarme

\footnotetext{
${ }^{28}$ J. L., Picoche, «¿Existe el romanticismo en España?», en D. T. Gies (ed.), El romanticismo, Madrid, Taurus, 1989, p. 278.
} 
de vos; pero temed, ¡vive Dios...!» [II, 3, p. 27]) para arrepentirse inmediatamente y rebajar la posición de superioridad que ha mantenido hasta ese momento:

Álvaro. [...] Mal os pudiera ofender

y vuestro amor no acatar

quien tanto vos supo amar

como os supo merecer.

Sabréis el tiempo adelante

lo que vos perdéis conmigo,

y si ahora es enemigo

quien os fue una vez amante.

Mi delito fue quereros,

y hacer como al rey servicios;

mi bien, vuestros beneficios,

y mi desgracia perderos.

(II, 3, p. 29).

Don Álvaro ama a la reina hasta su final; conocida la sentencia de muerte y a pocas horas de ser llevado al cadalso, pide a su criado Gotor que la busque para poder verla antes de morir, consciente en todo momento de que la causa de su agonía es la injerencia de su pasión en sus ansias de poder $^{29}$. El reconocimiento de este amor es siempre privado en Isabel y así se mantiene a lo largo de la obra hasta que el ajusticiamiento del condestable la transforma en el personaje que grita y se mesa el cabello, en la «dama blanca» propia del drama romántico ${ }^{30}$. Isabel pide perdón al rey porque «queríamos sin lesión; amores no ofenderán/ los que para nadie son/ si ocultos al mundo están» (II, 9, p. 39). La debilidad del rey no solo se manifiesta en el ámbito político, sino también en el personal. Sus dudas, vacilaciones y cambios de parecer son constantes y en varias ocasiones manifiesta que no sabe a quién debe creer $^{31}$.

Doña Isabel es una mujer apasionada, que defiende su honra y su orgullo, pero que, románticamente escindida entre la razón y la pasión, no puede dejar de amar al condestable. De ahí sus gritos de horror cuando es consciente de que don Álvaro será ajusticiado (IV-1, 5, p. 69) y al final de la obra, cuando el condestable muere (IV-2, 10, p. 83), o su exhibición de dolor ante los nobles y el rey. Isabel había reclamado justicia incluso pidiendo la muerte de Luna (VI-1, 5, pp. 67-68) para demostrar su honor.

\footnotetext{
${ }^{29}$ «ÁltVARO: [...] ¡Y que el hombre al mal sucumba/ por un amor que te aguce!/ En su pecho la voz zumba/ de una hermosa, y le conduce/ al delirio o a la tumba./ Vi una corona al nacer/ que eterno afán me produjo./ Vi un cielo en una mujer/ que a un infierno me condujo,/ y un cadalso al fallecer». (IV-2, 4, pp. 74-75).

${ }^{30} \mathrm{M}$. Ribao Pereira, «La locura femenina como resorte espectacular: obnubilación, delirio y demencia en el drama romántico», Letras Peninsulares, 12, 2 (1999), pp. 185-199.

31 «REY: ¡Vive Dios, doña Isabel,/ que el seso vais a quebrarme!/ Loco estoy por vida mía,/ y juro no entiendo a nadie./ Conmigo mismo luchando/ tengo esfuerzo y soy cobarde;/ ¡ni venzo ni soy vencido...!». (I, 5, p. 21).
} 
Finalmente la pasión es más fuerte y suplica por la vida de su amado ${ }^{32}$.

Uno de los grandes apoyos de don Álvaro en la obra es don Alonso de Vivero, el contador del reino. Se mostrará leal al condestable hasta su final, pese a que don Álvaro cree que lo ha traicionado y por ello lo defenestra, otro de los motivos por los que se precipita el encarcelamiento de Luna. A don Alonso se le presenta como un hombre poderoso e importante ${ }^{33}$.

El obispo don Alonso actúa como representante de los nobles en la obra; su figura y sus acciones se ciñen, a grandes rasgos, a las que transmiten las fuentes historiográficas de la primera mitad del siglo XIX ${ }^{34}$. Su primera intervención ya es una conspiración contra don Álvaro y su conversación con el rey representa el punto de inflexión que hace que Juan II se posicione en contra de su valido (I, 3, p. 12). Su papel es también el de procurar la reunión de los nobles con el monarca, de nuevo con la finalidad de acabar con el condestable. Al igual que don Juan, teme a Luna; y cuando este está a punto de ser llevado a la cárcel, le dice que no tiene nada que ver con su arresto (III, 8, p. 58). La función de los nobles, como la del obispo, se limita a conspirar motivados por un ansia personal de poder que en nada beneficia al reino:

\author{
Álvaro. [...] Mas, ¿qué virtud os movió \\ para hacer en mi venganza? \\ ¿Mis tesoros? ¿Mi privanza? \\ Pues sois peores que yo. \\ Ponéis acerados yugos \\ a los que llamáis vasallos. \\ ¿Y qué hacéis sino roballo, \\ y ser sus fieros verdugos? \\ Cruel llamaisme y feroz \\ porque sé vengar el trono, \\ y al mismo que yo perdono \\ matarais por una voz. \\ Decís que el real tesoro
}

\begin{abstract}
${ }^{32}$ Atendiendo a la verdad histórica, cabe matizar que Bonilla da un giro completo a la relación de doña Isabel y don Álvaro. Como sucede habitualmente en los dramas históricos románticos, Bonilla concentra en la acción amorosa los argumentos no históricos de la pieza, que determinan el desenlace de la trama pública, más o menos próxima, según los casos, a los testimonios historiográficos. Como resume Quintana, el condestable quizás había intervenido en la vida privada de los monarcas, al igual que había hecho en el anterior matrimonio de don Juan con María de Aragón. Parece ser que la reina Isabel, que accede al trono de Castilla a través de una unión defendida frente a otras opciones por el propio Luna, se posicionó en contra de don Álvaro desde el comienzo del matrimonio (M. J. Quintana, ob. cit., p. 204).

${ }^{33}$ Alonso de Vivero en los primeros años junto al condestable había sido leal, pero en los últimos tiempos, cercanos al ajusticiamiento de don Álvaro, cuando este no contaba con la confianza del rey, había conspirado contra él (M. J. Quintana, ob. cit., pp. 215-216).

${ }^{34}$ Hasta mediados de siglo, los escritores asumen como históricos los datos aportados tanto por los compendios históricos previos (la Historia de España del padre Mariana, sobre todo), como por ensayos (el ya mencionado de Quintana) e incluso por textos literarios, sobre todo el romancero.
\end{abstract}


mal agoté, demás de esto,

y si llegáis a mi puesto,

no dejaréis pieza de oro.

Por esto yo os declarara

guerra hasta la tumba fría.

Si en mí Castilla perdía,

nada en vosotros ganara.

(III, 5, pp. 51-52).

El único personaje secundario que destaca en el ámbito coral de la conjura es el magistrado don Juan, que renuncia a su cargo tras el juicio en el que se condena a don Álvaro. Se presenta ante Juan II para pedir justicia y se niega a firmar la sentencia porque

Don JuAN: [...] ha sido condenado sin el orden y formalidades prescritas por leyes del reino. Condénasele sin ser oído ni defendido. ¿Quisiérades, don Juan II, que el hacha del verdugo se convirtiera en daga homicida? ¿Quisiérades, señor, que al entrar el reo en la cárcel pusiéranle una mordaza y no le cayera hasta el cadalso? Si esto consentís, encended una hoguera delante del ajusticiado y echad la ley a las llamas. (IV-1, 3, p. 64).

Visita a don Álvaro (IV-2, 4, pp. 74-75) para mostrarle su indignación con la justicia y ofrecer apoyo al reo y, finalmente, cierra el drama arrojando su toga a los pies del rey ${ }^{35}$. Los últimos versos de la obra inciden, pues, en el tema fundamental de la misma: la arbitrariedad del poder que se ejerce sin otra guía que la ambición y los intereses particulares.

La mayoría de los personajes viven víctimas de sus pasiones o intereses privados y todos, de un modo u otro, son desgraciados. El conflicto dramático esencial es el choque de intereses entre don Álvaro y los demás ricoshombres castellanos. Durante la reunión de los nobles con el rey, fijada por el obispo don Alonso, el conde de Plasencia sintetiza los males que cercan a la corona castellana:

Plasencia: [...] El príncipe don Enrique huyose ya de la corte y os niega la obediencia; los infantes de Aragón hacen liga contra su Alteza, los moros, mas escarmentados en el encuentro de Lorca, harán entrada por tierras de Andalucía y el que antes temía vuestra pujanza, nuestro acero dentro de los muros de Granada, vendrá a clavar el suyo en las arenas del Pisuerga, o en las orillas del Tajo. (II, 6, p. 32).

Como ya he mencionado, Bonilla establece un claro paralelismo entre este contexto político y el de su propio tiempo. Son constantes las alusiones al «enemigo navarro» en un guiño del escritor al primer conflicto carlista, que comienza en 1833 tras la muerte de Fernando vir y que durará hasta 1840. Su eje se hallaba, a la altura

\footnotetext{
35 «Don Juan. [...] ¡Don Juan II de Castilla! Oíd./ Yo os devuelvo la odiosa autoridad,/ y honor que vos me disteis: la tomad,/ que nunca me verá Valladolid». (IV-2, 10, pp. 83).
} 
de 1838, en el País Vasco y en Navarra y la contienda se puede reconocer en la obra a través de las referencias bélicas que inserta el dramaturgo.

La primera pista la ofrece don Alonso de Vivero mientras conversa con don Álvaro en el acto I: «obrad con acierto, don Álvaro. Nuevas revueltas amenazan Castilla, y la guerra con los navarros la aguzan los grandes» (I, 1, p. 6). Lo que estaba en juego en la época de Bonilla era no solo quién ocuparía el trono, sino el régimen político bajo el que se iba a gobernar España. El dramaturgo, que vitalmente, como he explicado ya, adopta una clara postura anticarlista, encuentra en el enfrentamiento de Luna con el rey de Navarra un pretexto para la expresión de su propia ideología liberal. De hecho, podría establecerse un cierto paralelismo histórico entre la proximidad del rey de Navarra - que asoma por Burgos con intención de ocupar la corte, en palabras de don Juan (I, 2, p. 9) - con la llamada Expedición Real de 1837, en la que el pretendiente al trono, Carlos María Isidro de Borbón, parte de Navarra avanzando hacia la corte para destronar a Isabel $\mathrm{II}^{36}$.

El desafío a las instituciones es una constante en el personaje de don Álvaro. No solo se enfrenta al rey, sino a los nobles y a la iglesia de forma continuada a lo largo del drama, tanto en el ámbito personal como en el público. En la línea del romanticismo político de los años 30, se identifican los postulados de la nueva estética con el compromiso liberal. De ahí que, con cada uno de sus actos, Luna camine indefectiblemente hacia el cadalso, es decir, hacia su condición de héroe. Es en este hecho donde radica lo que Caldera ${ }^{37}$ calificó como la auténtica revolución romántica.

En definitiva, el drama de Bonilla refleja acontecimientos políticos y sociales de la época del dramaturgo a través de los conflictos de la corte de Juan in que lleva a escena, tales como el desgaste del sistema gubernamental o la deslegitimación de la corona, todo ello imbricado en el liberalismo progresista que expone como ideología el texto. Ello se lleva a cabo a través de personajes que se acercan a patrones de tipo convulsivo y subversivo. Destaca don Álvaro de Luna, un personaje enfrentado a todos los cortesanos y a la iglesia, en constante desafío a las instituciones. Las luchas que se generan a su alrededor evocan directamente a Mendizábal, que llegó a convertirse en una figura clave durante algunos años en el devenir político de España. Como don Álvaro, se había ganado la animadversión de la aristocracia y de la iglesia y ambos acaban siendo abandonados por la corte.

El autor manifiesta su malestar ante la inestabilidad política de la época, pues

\footnotetext{
${ }^{36}$ R. Carr, España 1808-1975, Barcelona, Ariel, 1984, p. 193.

${ }^{37}$ E. Caldera, «De lo que hoy se llama romanticismo», Siglo diecinueve (Literatura hispánica), 1 (1995), pp. 77-90.
} 
la contienda carlista estaba en un momento de especial recrudecimiento en el tiempo en que se publica y estrena el drama. No parecen casuales, por tanto, las constantes menciones a los principales focos del conflicto, especialmente Navarra. Del mismo modo, se sugiere la presencia del pretendiente al trono a través de diversas alusiones a los infantes de Aragón y a los bandos de Castilla. Bonilla presenta un escenario de lucha centrado, básicamente, en intereses privados y critica la situación de la corte, en constantes disputas internas -entre liberales moderados y liberales progresistas- y externas, en relación a la amenaza carlista. Para integrar estas luchas por el poder en una trama dramáticamente atractiva, Bonilla añade una línea amorosa que se aparta de lo histórico pero no de la verosimilitud. Todo ello se enmarca en técnicas novedosas de representación, que suponen, como en la totalidad de las obras de su tiempo, una verdadera revolución en el teatro.

El texto sirve como instrumento de denuncia del absolutismo y de la desgracia individual y colectiva a que conducen las luchas por el poder y el desgobierno. En este sentido, Don Álvaro de Luna, Condestable de Castilla es un buen ejemplo de la importancia de los textos olvidados y de la necesidad de recuperarlos, ya que ahondan en las cuestiones estéticas de su periodo y abren líneas productivas de investigación.

\section{Bibliografía}

ANÓNIMO, «Gacetín urbano», El Constitucional (14 mayo 1840) p. 4. , «Producciones literarias de don José María Bonilla», El Constitucional (30 agosto 1841) p. 4.

, «A nuestros lectores», El Popular. Diario de los Intereses de Cataluña (30 septiembre 1841), s. p.

, «Crónica de teatros», El Clamor Público (30 octubre 1845), p. 4.

Bonilla, J. M., Poesías, Valencia, Imprenta a cargo de V. Lluch, 1840.

, «A nuestros suscritores», El Popular. Diario de los Intereses de Cataluña, 8 diciembre (1841), s. p.

Don Álvaro de Luna, Condestable de Castilla, Madrid, Imprenta de C. González, 1856.

BurdiEL, I., Isabel II: una biografia (1830-1904), Madrid, Taurus, 2010.

CALDERA, E., «De lo que hoy se llama romanticismo», Siglo diecinueve (Literatura hispánica), 1 (1995), pp. 77-90.

CARr, R., España 1808-1975, Barcelona, Ariel, 1984.

Codeseda troncoso, F., «Un romance decimonónico desconocido: El castigo de un mal juez, de Adolfo de Castro y Rossi», en R. Hernández Arias, G. Rivera Rodríguez, S. 
Cuba López y D. Pérez Álvarez (eds.), Nuevas perspectivas literarias y culturales, Vigo, MACC-ELICIN, 2016, pp. 97-104.

EscobaR, J., «Romanticismo y revolución», en D. T. Gies (ed.), El Romanticismo, el escritor y la crítica, Madrid, Taurus, 1989, pp. 320-335.

Flores, J. M. de, Crónica de don Álvaro de Luna, Madrid, Sancha, 1784.

Hidalgo, D., Diccionario General de la Bibliografía Española, Madrid, Julián Pena, 1867

Laguna, A. y E. Ortega, Un periodista romántico en la revolución burguesa: José María Bonilla, Valencia, Papers de Prensa, 1989.

Laullé, J., Biografía en abreviatura de D. José María Bonilla, Valencia, Imprenta de José Domenech, 1871.

Peers, E. A., Historia del movimiento romántico español, Madrid, Gredos, 1973, 2 vols.

PICoche, J. L., «¿Existe el romanticismo en España?», en D. T. Gies, (ed.), El romanticismo, Madrid, Taurus, 1989, pp. 269-303.

Quintana, M. J., Vidas de españoles célebres, Madrid, Imprenta de Burgos, 1833, tomo III: Don Álvaro de Luna.

Ribao Pereira, M., «La locura femenina como resorte espectacular: obnubilación, delirio y demencia en el drama romántico», Letras Peninsulares, 12, 2 (1999), pp. 185199.

«Una relectura romántica de la corte: Los cortesanos de don Juan II, de J. Morán» en J. M. González Herrán et al., eds., La historia en la literatura del siglo XIX. Barcelona, Universitat de Barcelona, 2017, pp. 651-660.

, «¿Y si el corazón miente? Los (falsos) poetas cortesanos de Juan II vistos por los dramaturgos románticos», en A. Cancellier, ed., El corazón es centro, Padua, Universidad de Padua, 2017 (en prensa). 